\title{
Water use efficiency of Irish dairy processing
}

\section{M.-J. Yan* and N. M. Holden}

UCD School of Biosystems and Food Engineering, University College Dublin, Dublin 4, Ireland

\begin{abstract}
Dairy processing uses a significant amount of water for processing and cleaning. Withdrawing and distributing water and treating wastewater represent significant costs to the Irish dairy processing industry. Stringent discharge limits also add pressure for water use efficiency, particularly during peak production months. Improving water use efficiency is therefore critical for Irish dairy processing. We conducted a detailed analysis of water use efficiency in 4 Irish dairy processing plants. Using farm gate to processor gate (gate-to-gate) life cycle assessment, we assessed on-site water data quality and investigated gate-to-gate volumetric water use and eutrophication potential (EP) for 3 common dairy products. We also benchmarked the on-site water use and water balance, characterized wastewater nutrient load, analyzed the influencers of on-site water use, and identified scope for increased water use efficiency. We found that condensate from evaporation represented a significant input at the site level $(0.51$ to $1.14 \mathrm{~L} / \mathrm{L}$ of fresh water purchased or extracted from nature). In terms of gate-to-gate volumetric water use, butter used 1,326 to $1,843 \mathrm{~m}^{3} / \mathrm{t}$ of solids, with electricity being the largest contributor, whereas milk powders used 3,006 to $3,754 \mathrm{~m}^{3} / \mathrm{t}$ of solids, with electricity and ingredients being the largest contributors. Eutrophication of butter was found to be 0.51 to $0.77 \mathrm{~kg}$ of $\mathrm{PO}_{4}$ equivalents (eq)/t of solids, with transportation and nutrient emissions from wastewater treatment being the largest contributors. Eutrophication of milk powder was found to be 0.96 to $3.35 \mathrm{~kg}$ of $\mathrm{PO}_{4} \mathrm{eq} / \mathrm{t}$ of solids, and contributions varied depending on powder specifications. Milk intake water use and various leakages were found to be hotspots that could be managed to reduce water use on site. Comprehensive metering is urgently needed to improve water use efficiency in light of the ongoing expansion of dairy production and hence processing in Ireland. Significant opportunities exist to optimize operator behavior, water reuse, and off-site transporta-
\end{abstract}

Received February 20, 2019.

Accepted May 12, 2019.

*Corresponding author: mingjia.yan@ucd.ie tion and energy. This study represents the first attempt to define water efficiency opportunities both at the site level and along the supply chain. Processors need to be aware of off-site contributors that significantly affect both volumetric water use and environmental impacts of processed dairy products.

Key words: dairy processing, eutrophication, life cycle assessment, wastewater

\section{INTRODUCTION}

Dairy is critical to the Irish agri-food sector, with an export value of approximately $€ 4.0$ billion in 2017, accounting for $30 \%$ of food and drink exports (Bord Bia, 2017). The removal of European Union milk quotas in 2015 brought new opportunities and an ambitious target of a 50\% increase of milk production by 2020 (DAFM, 2010). Water use efficiency is a particular challenge. The literature suggests that global dairy processing uses 0.2 to $11 \mathrm{~L}$ of water per L of milk (Daufin et al., 2001), $28 \%$ of which is used for cleaning-in-place (CIP; Prasad et al., 2005). Water is used as an energy carrier for heating and cooling, as a material for cleaning, and as a transporter of chemicals and nutrients; therefore, withdrawing and distributing water and treating the resulting wastewater represent a significant cost. In Ireland, wastewater discharge limits imposed by Irish Environmental Protection Agency add pressure to water use efficiency, especially given the fact that Irish milk production follows a seasonal pattern (Figure 1). Improving water use efficiency is therefore critical for the future expansion of dairy processing in Ireland. Life cycle assessment is a tool to assess potential environmental impacts from raw material acquisition through production, use, recycling, and final disposal (ISO, 2006). Water footprint is a concept related to life cycle assessment and it specifically assesses the quantity of water used and the environmental impacts related to water (ISO, 2014). As water is an essential natural resource, its use and management is critical for business globally, and water footprint has been applied to many agri-food products (Gerbens-Leenes et al., 2009; Lovarelli et al., 2016) including dairy products (Djekic et al., 2014; Bai et al., 2018; Mahatha et al., 2019). 
The water footprint of agri-food products sometimes focuses on the agricultural stage because of its large contribution (Lovarelli et al., 2016). Water footprint of dairy products, however, does not provide enough information about water use efficiency and wastewater reduction at the processing level because water use is related to energy consumption, operational efficiency, and infrastructure constraints. There are few published analyses of water use for dairy processing at the unit process level (Depping et al., 2017), but little data are available where plants produce multiple products such as butter and skim milk powder (SMP). Geraghty (2011) benchmarked water use at 15 Irish dairy processors from 2006 to 2009 and found that mean water use $\left(\mathrm{m}^{3} / \mathrm{t}\right.$ of milk processed) decreased by $18 \%$ over this time period. However, that study suffered from a lack of transparency and the variation among companies and scope for improvement was not clear. Finnegan et al. (2017) analyzed average environmental impacts of butter and SMP at 5 processing sites. That study included very little information about the breakdown of water use or its impacts on water depletion and nutrient discharged. As the dairy industry in general, and particularly in Ireland where milk supply is seasonal, is concerned about benchmarking of fresh water used and the nutrient load of treated effluent, a more detailed, plant-specific analysis is timely.

To benchmark Irish dairy processors and identify scope for future developments, the objectives of this study were to (1) understand the quantity of water use by dairy processing through unit processing steps; (2) benchmark on-site water use, wastewater generation, and wastewater nutrient load (using fresh water eutrophication, EP); (3) identify the influencers of on-site water use; and (4) identify the scope of increased water use efficiency.

Our focus was gate-to-gate rather than the full life cycle because there is no evidence to suggest the milk supply from the farm stage would affect the processing stage. Likewise, there is no evidence to suggest that downstream markets differ among the studied products and companies so this stage was also omitted. A similar approach has been taken by previous studies designed for benchmarking (Nutter et al., 2013; Finnegan et al., 2017).

\section{MATERIALS AND METHODS}

We conducted site visits at 6 dairy processing companies and collected site-specific data from 2014 and 2015. Only 4 companies (A, B, C, and D) could provide sufficient water data to allow benchmarking. Analysis of companies A, C, and D was based on 2015 data and analysis of company B was based on 2014 data. We analyzed 3 products from the 4 companies: butter (butter-A, butter-B, butter-C), SMP (SMP-A, SMP-C, SMP-D), and fat-filled powder (FFP, FFP-B).

For details regarding scope, allocation, and general description of the system, refer to Yan and Holden (2018). The functional unit was $1 \mathrm{~kg}$ of solids in the final product (butter or powder). The system boundary was from the farm gate to the processor gate (gate to gate), including upstream activities (fresh water supply, energy production and transportation/trans-

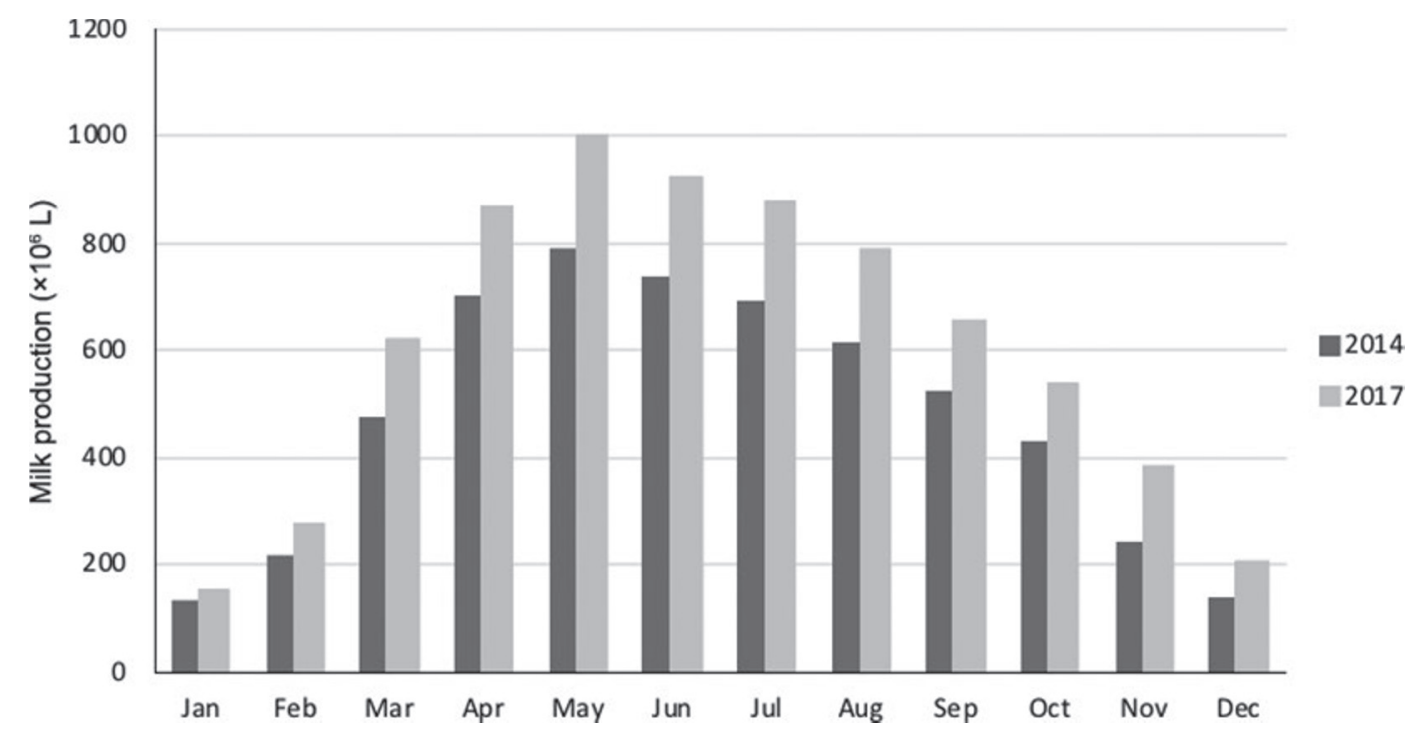

Figure 1. Seasonal cow milk production in Ireland, illustrated from intake of milk by Irish creameries and pasteurizers from domestic sources in 2014 and 2017 (before and after abolition of milk quotas in 2015; CSO, 2017). 
Table 1. Water use and effluent treatment from company A (2015), B (2014), C (2015), and D (2015) (in L/t of total milk processed by the site unless otherwise indicated)

\begin{tabular}{|c|c|c|c|c|}
\hline Item $^{1}$ & $\mathrm{~A}$ & $\mathrm{~B}$ & $\mathrm{C}$ & $\mathrm{D}$ \\
\hline \multicolumn{5}{|l|}{ Water use (L/t of total milk processed) } \\
\hline Whole milk intake (lorry) & 107.3 & $\mathrm{NA}^{2}$ & NA & NA \\
\hline Whole milk intake (milk tanker) & NA & 60.8 & NA & 260.6 \\
\hline Whole milk separation and pasteurization & 29.6 & 33.6 & NA & NA \\
\hline Butter & 77.6 & 76.5 & NA & 0.0 \\
\hline Casein products & 276.0 & 0.0 & NA & 254.5 \\
\hline Evaporation & NA & 111.6 & NA & 309.5 \\
\hline Drying (excluding casein) & NA & 113.8 & NA & \\
\hline Boilers & 27.2 & 25.3 & NA & 39.6 \\
\hline Refrigeration make-up water & 32.4 & NA & NA & 40.0 \\
\hline CIP of silos, tanks, feeding lines, and so on & 387.7 & 104.7 & NA & 202.6 \\
\hline Cooling tower make-up water & NA & NA & NA & 83.8 \\
\hline Other & 28.9 & NA & NA & 337.7 \\
\hline Unaccounted & 387.7 & 243.0 & NA & 498.5 \\
\hline Total water use & $1,348.1$ & 769.3 & $1,748.9$ & $2,026.9$ \\
\hline Total water use ( $\mathrm{m}^{3} / \mathrm{t}$ of products $)$ & 9.5 & 3.6 & 6.6 & 7.4 \\
\hline Total water use $\left(\mathrm{m}^{3^{3}} / \mathrm{t}\right.$ of product solids) & 10.4 & 3.9 & 11.4 & 11.4 \\
\hline \multicolumn{5}{|l|}{ Effluent treatment } \\
\hline Effluent treated/milk processed (L/L) & 1.8 & 1.3 & 1.2 & 3.2 \\
\hline Effluent treated/water supplied $(\mathrm{L} / \mathrm{t})$ & 1.3 & 1.8 & 0.6 & 1.5 \\
\hline Electricity $/ \mathrm{COD}$ reduction $(\mathrm{kWh} / \mathrm{kg})$ & 0.9 & 1.1 & 0.8 & 0.6 \\
\hline \multicolumn{5}{|l|}{ Treated effluent from WWTP } \\
\hline $\mathrm{COD}\left(\mathrm{mg}\right.$ of $\left.\mathrm{O}_{2} / \mathrm{L}\right)$ & NA & 31.6 & 42.1 & 24.1 \\
\hline Total $\mathrm{NH}_{3}-\mathrm{N}(\mathrm{mg} / \mathrm{L})$ & 1.70 & 0.08 & NA & 0.35 \\
\hline Total orthophosphate P (mg/L) & 0.41 & 0.28 & 2.60 & 0.26 \\
\hline
\end{tabular}

${ }^{1} \mathrm{CIP}=$ cleaning in place COD $=$ chemical oxygen demand; WWTP $=$ wastewater treatment plant .

${ }^{2} \mathrm{NA}=$ not available.

mission, production and transportation of ingredients, chemicals and packaging materials, and transportation of whole milk from farm to processor), on-site activities [common and product-specific processing, wastewater treatment plant (WWTP)], and downstream activities (transportation and disposal of solid wastes). Water use in this study refers to degradative usage; therefore, cooling water and chilled water were not included because they are used without direct contact with products and therefore without degrading the quality of the water. Table 1 presented details of water use and effluent treatment for each company. In addition, to quantify the gate-to-gate volumetric water use and impact, we chose impact category EP from CML-IA baseline v3.04 (van Oers, 2015) implemented in Simapro 8.2 (PRé Consultants, 2019).

We assessed the data quality of water in this study based on a pedigree matrix (Ciroth et al., 2016). This was implemented by first assessing data completeness from the 4 companies (presented in Yan and Holden, 2018). Based on the companies' situations, we modified the completeness criteria and defined a set of completeness scores (on a scale of 1 to 5) based on Ciroth et al. (2016): $1=$ complete; $2=$ incomplete, $<50 \%$ data missing; $3=$ incomplete, $>50 \%$ data missing, or data were based on communication with staff; $4=$ submetering was lacking and data were combined with other measurement; and $5=$ no data. Finally, we averaged completeness scores with other scores (reliability, geographical/temporal correlation, future technology correlation) to obtain the data quality score.

It is important to note that for a dairy processor, water input comes not only from the water supply (from lake, river, or borehole) but also from milk and other food ingredients. Condensate from evaporation of dairy products (e.g., whole milk, skim milk, whey), sometimes called "cow water" (Prasad et al., 2005), is a significant water input that is recycled for dairy processing (Daufin et al., 2001). To differentiate different sources of water, we refer to water sourced from lake, river, or borehole as fresh water.

To understand the influencers of total water use $(\mathrm{L} / \mathrm{t}$ of milk), we conducted one-way ANOVA using R ( R Core Team, 2018) based on 12 mo of data from companies A, B, and D. We used the "aov" function in R (Chambers et al., 1992) and used company ID (A, B, or D) as random effect, months as fixed effect, and nested months within company ID. In theory, total water use equals sum of water use from individual plants, which depends on CIP procedures and product mix. Based on Wojdalski et al. (2013), we believed that energy consumption could help explain the water use of a plant, as water use requires energy. We also believed that the seasonal production and product mix might affect wa- 
Table 2. Water data quality of butter and powder products; completeness was scored by averaging relevant processes according to Yan and Holden (2018)

\begin{tabular}{|c|c|c|c|c|c|c|c|}
\hline \multirow[b]{2}{*}{ Quality parameter } & \multicolumn{7}{|c|}{ Product $^{1}$} \\
\hline & Butter-A & Butter-B & Butter-C & SMP-A & FFP-B & SMP-C & SMP-D \\
\hline Completeness & 3 & 2 & 5 & 3 & 2 & 5 & 4 \\
\hline Temporal correlation & 1 & 1 & 1 & 1 & 1 & 1 & 1 \\
\hline Geographical correlation & 1 & 1 & 1 & 1 & 1 & 1 & 1 \\
\hline Future technological correlation & 2 & 2 & 2 & 2 & 2 & 2 & 2 \\
\hline
\end{tabular}

${ }^{1} \mathrm{SMP}=$ skim milk powder; FFP $=$ fat-filled powder.

ter use. We therefore chose the following 9 parameters to explore their effect on monthly water use per tonne of milk processed: separation and pasteurization electricity $(\mathrm{kWh} / \mathrm{t}$ of milk), butter plant electricity $(\mathrm{kWh} / \mathrm{t}$ of butter), SMP evaporation and drying electricity $(\mathrm{kWh} / \mathrm{t}$ of SMP), utility electricity (boiler house and combined heat and power, refrigeration, compressed air, $\mathrm{kWh} / \mathrm{t}$ of milk), electricity used by WWTP $\left(\mathrm{kWh} / \mathrm{m}^{3}\right.$ of effluent), steam generation ( $\mathrm{kg}$ of steam $/ \mathrm{t}$ of milk), ratio of total product DM to milk solids (\%), chemical oxygen demand (COD) of WWTP inflow (mg of $\mathrm{O}_{2} / \mathrm{L}$ ), and ratio of monthly milk separation to annual total (\%). We selected significant contributors based on their significance. Data used in one-way ANOVA of water use are presented in Supplemental Table S1 (https://doi.org/10.3168/jds.2019-16518).

The following water was used at the processing sites under study. (1) Cleaning: water is used for cleaning purposes throughout all processing stages. This includes external wash of milk lorries (after each delivery) and silos (varied among companies) and internal wash of equipment (CIP). Depending on the company, water may be fresh water, steam condensate, or cow water. (2) Processing: water is used for product-specific processing such as washing casein curd and preparing ingredient solutions (e.g., salt for butter and sugar for powder). Processing water is predominantly from fresh water. (3) Utilities: water is fed to boilers to generate steam to provide heat treatment for processing. After heat exchange, steam condenses to provide preheating functions. Water is also used as make-up for leakages in the refrigeration system and evaporation and blowdown in cooling towers. Water may be fresh water, steam condensate, or cow water.

\section{RESULTS}

\section{On-Site Water Data Quality}

Butter-A, butter-B, FFP-B, and SMP-D had good data quality (they scored $<2$ ), whereas butter-C, SMP-
A, and SMP-C had poor data quality $(>2)$, especially for reliability and completeness (Table 2). Company D did not produce butter and thus butter-D was not scored. We only analyzed volumetric water for butterA, butter-B, FFP-B, and SMP-D. Analysis of EP, in contrast, was not dependent on volumetric flow of water because the nutrient concentration of treated effluent was allocated based on product solids. The WWTP of company D processed wastewater from other sites and the treated effluent could not be easily allocated to products. We therefore only analyzed EP of butter-A, butter-B, butter-C, SMP-A, SMP-C, and FFP-B.

\section{Overall Water Use and On-Site Water Balance}

Total water use varied among the 4 companies, ranging from 769.3 to $2,026.9 \mathrm{~L} / \mathrm{t}$ of milk processed (Table 1). Companies A and D used a considerable amount of water $(276.0$ and $254.5 \mathrm{~L} / \mathrm{t}$ of milk processed, respectively) for casein processing and casein plant cleaning. Cleaning of evaporators and dryers also consumed a lot of water (225.4 to $309.5 \mathrm{~L} / \mathrm{t}$ of milk processed), as did CIP of silos and feeding systems (104.7 to $387.7 \mathrm{~L} / \mathrm{t}$ of milk processed). Measurement of water use in the plants was found to be insufficient in many cases. For the 3 companies that had submetering records during 2014 to $2015,24.6$ to $31.6 \%$ of total water was without submetering ("Unaccounted," Table 1).

The general water balance graph (Figure 2) shows the inputs, outputs, and circulation of water in the form of fresh water, steam, condensate, and chilled water. In addition to fresh water, cow water represented a significant input, from 0.51 to $1.14 \mathrm{~L} / \mathrm{L}$ of fresh water. The majority of cow water is recompressed into steam to reduce the live steam use in multi-effect evaporators; at the end, it is filtered and used as the main source of boiler feed water. The rest of the cow water is used to make up CIP solutions, to wash trucks, or sent to the cooling tower. The majority of fresh water was used for processing and CIP (0.92 to $0.96 \mathrm{~L} / \mathrm{L}$ of fresh water). Comparing the 2 inputs to WWTP (ignoring 


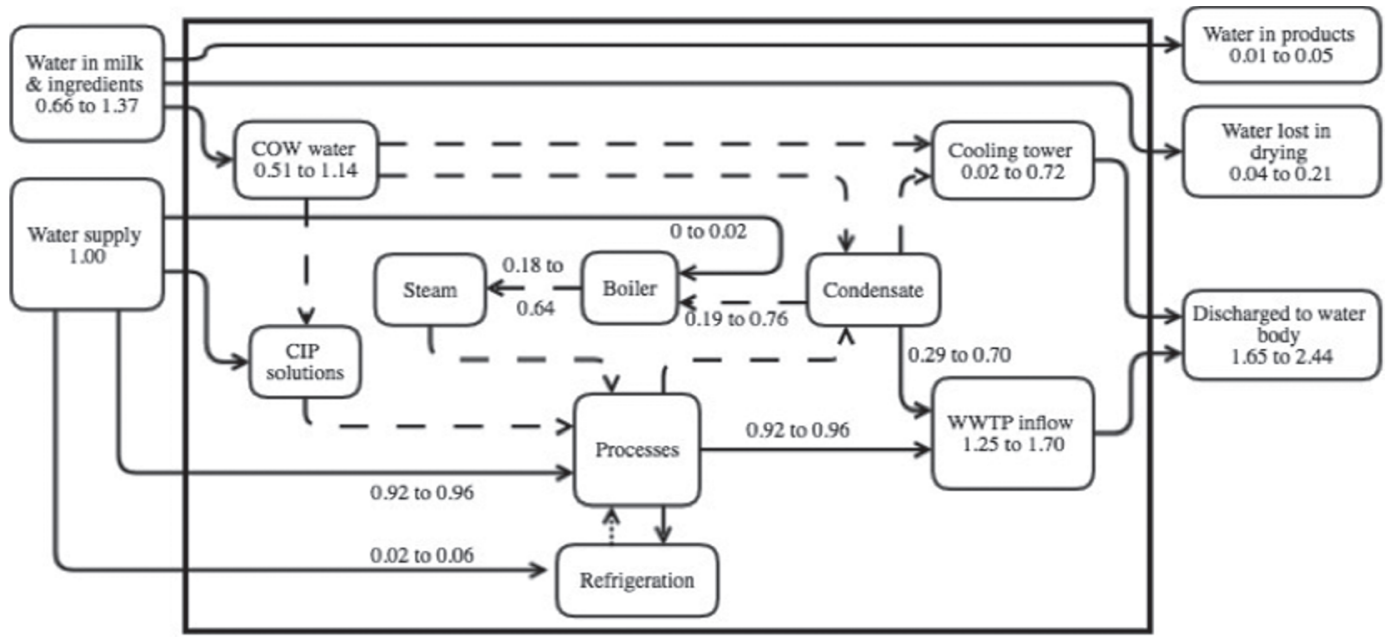

Figure 2. A general diagram of the water balance for the Irish dairy processors used for this study. Numbers indicate mass of water scaled against mass of fresh water supply based on companies A, B, and D. Solid border indicates a site boundary; dashed, dotted, and solid arrows indicate warm, chilled, and fresh water streams, respectively. Boiler blowdown rate was assumed $15 \%$. Condensate contribution to raw effluent was estimated by assuming all water into processing and cleaning-in-place (CIP) ends up in the wastewater treatment plant (WWTP). Note that minor streams such as storm water, ingredient make-up, and lorry wash are omitted.

other minor inflow such as lorry wash), the condensate contribution was estimated to be 23 to $41 \%$, whereas effluent from processing and CIP made up the rest. The majority of water output was discharged to a receiving water body (1.65 to $2.44 \mathrm{~L} / \mathrm{L}$ of fresh water).

\section{Effluent Characteristics}

Raw effluent from individual processing plants was often combined into 2 or 3 streams and then pumped into WWTP on site. Characteristics were therefore often only available for combined raw effluent. Figure 3 shows the monthly COD concentration of raw effluent into WWTP. Raw effluent from the whey plant of company D had the highest COD concentration (3.3 to $5.0 \mathrm{~kg}$ of $\mathrm{O}_{2} / \mathrm{m}^{3}$ ), followed by combined raw effluent other than the casein line of company A (A-rest, 1.9 to $5.5 \mathrm{~kg}$ of $\mathrm{O}_{2} / \mathrm{m}^{3}$ ), and combined raw effluent other than the cheese line of company C (C-rest, 2.3 to 4.1 $\mathrm{kg}$ of $\mathrm{O}_{2} / \mathrm{m}^{3}$ ). Note that A-rest included whey permeate (after membrane filtration of raw whey), which could explain the high COD concentration. Cheese lines were found to have low COD concentrations (0.1 to $3.9 \mathrm{~kg}$ of $\left.\mathrm{O}_{2} / \mathrm{m}^{3}\right)$.

Treated effluent from WWTP achieved significant COD reduction, from 98.9 to $99.4 \%$. In terms of effluent discharge limits, company $\mathrm{C}$ reached 84 to $92 \%$ of the limit between March and August 2015, and company D reached 83 to $98 \%$ of the limit between April and October 2015. Company B, in contrast, had sufficient capacity of WWTP and only reached 61 to $64 \%$ of the discharge limit during May and June 2014. Monthly discharge data for company A were not available.

\section{Gate-to-Gate Volumetric Water Use}

Gate-to-gate volumetric water use is presented in Figure 4. Butter-A and butter-B used 1,843 and 1,326 $\mathrm{m}^{3} / \mathrm{t}$ of solids, respectively. Electricity was the largest contributor (64 to $65 \%$ ), followed by chemicals (18 to $24 \%$ ) and packaging (9 to $12 \%$ ). On-site water use had a very small contribution at the inventory level (2 to $3 \%$ ). Skim milk powder-D used $3,753.5 \mathrm{~m}^{3} / \mathrm{t}$ of solids. Electricity was the largest contributor (52\%), followed by chemicals (30\%) and fuel (10\%). On-site water use had a very small contribution at the inventory level $(2 \%)$. Fat-filled powder-B used $3,006.4 \mathrm{~m}^{3} /$ to of solids. Ingredients (vegetable oil) were the largest contributor $(41 \%)$, followed by electricity $(35 \%)$ and packaging $(8 \%)$. On-site water use had a very small contribution at the inventory level (1\%).

\section{Eutrophication Potentials}

The EP of butter-A, butter-B, and butter-C were $0.77,0.51$, and $0.53 \mathrm{~kg}$ of $\mathrm{PO}_{4}$ equivalents $(\mathbf{e q}) / \mathrm{t}$ of solids. For butter-B and butter-C, transportation was the largest contributor (29 to 41\%), followed by electricity (14 to $22 \%$ ) and chemicals (12 to $32 \%$ ). For butter-A, nutrient emissions from WWTP were the largest contributor $(32 \%)$, followed by transportation $(21 \%)$ and electricity (21\%). The EP of SMP-A and SMP-C was 


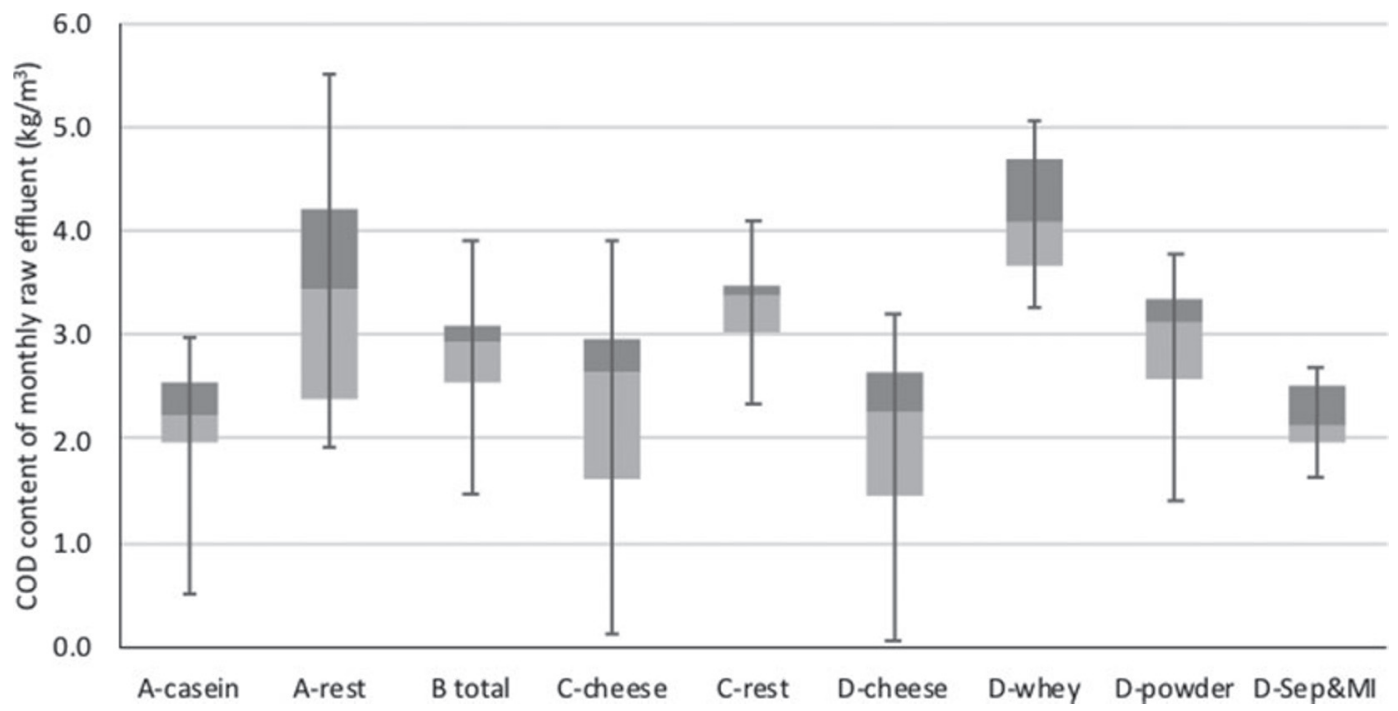

Figure 3. Chemical oxygen demand (COD) content of monthly raw effluent from the 4 companies. A-casein refers to raw effluent from the casein plant, and A-rest refers to combined raw effluent other than the casein line; C-cheese refers to raw effluent from the cheese plant, and C-rest refers to combined raw effluent other than the cheese line; D-whey and D-powder refer to raw effluent from the whey plant and powder plant, and D-Sep\&MI refers to combined raw effluent from separation/pasteurization and milk intake. Boxes show the first and third quartile and median; whiskers show the maximum and minimum values of the distribution.

1.25 and $0.96 \mathrm{~kg}$ of $\mathrm{PO}_{4} \mathrm{eq} / \mathrm{t}$ of solids. Chemicals were the largest contributor (26 to $34 \%$ ), followed by electricity (21 to $30 \%$ ) and on-site emissions (18 to $24 \%$ ). The EP of FFP-B was $3.35 \mathrm{~kg}$ of $\mathrm{PO}_{4} \mathrm{eq} / \mathrm{t}$ of solids. Ingredients (vegetable oil) were the most significant contributors (81\%) because of fertilizer run-off from producing the vegetables, with all others contributing less than $5 \%$ individually.

\section{Water Use in Unit Processes}

Milk Intake. Significant variations were found in water use for milk intake of companies $\mathrm{B}$ and $\mathrm{D}$, averaging from 60.8 to $260.6 \mathrm{~L} / \mathrm{t}$ of milk (Figure 5). Low efficiency was found at the beginning and end of the summer production season, especially in January and February.

Butter Production. Company A only recorded water use for butter production during the first half of 2015 because the meter failed and was not replaced. The median values showed that companies $\mathrm{A}$ and $\mathrm{B}$ used 1,469 and 1,273 L of water/t of butter.

Evaporation and Drying. Water use for evaporation and drying was only available from company B. Evaporators 1 and 2 used, on average, 128.1 and 59.8 $\mathrm{L} / \mathrm{t}$ of milk throughput (Figure 6 ), and dryers 1 and 2 used, on average, 974.7 and $396.5 \mathrm{~L} / \mathrm{t}$ of powder produced (Figure 7).

\section{Influencers of Water Use On-Site}

Results of one-way ANOVA (Table 3) indicated 2 parameters that significantly contributed to monthly water use per tonne of milk processed: separation and pasteurization electricity ( $\mathrm{kWh} / \mathrm{t}$ of milk), and utility electricity (boiler house and combined heat and power, refrigeration, compressed air; $\mathrm{kWh} / \mathrm{t}$ of milk).

\section{DISCUSSION}

We conducted a detailed analysis of water use efficiency across 4 Irish dairy processors, the first report of its kind in Ireland. The seasonality of production, which is different from that in many other countries, means that Irish processors need to be proactive in water use efficiency. Water use efficiency tends to be lower during off-peak than peak seasons because similar amounts of water are needed for cleaning and maintenance even when throughput of milk is lower. Because the industry has ambitious expansion plans, this work provided a baseline for first steps toward more sustainable operations by identifying key opportunities for improvement. The findings (e.g., water use at the process level) and methods (e.g., water balance graph) contribute to our knowledge of the global dairy processing industry, where detailed water efficiency is often not reported or analyzed. 


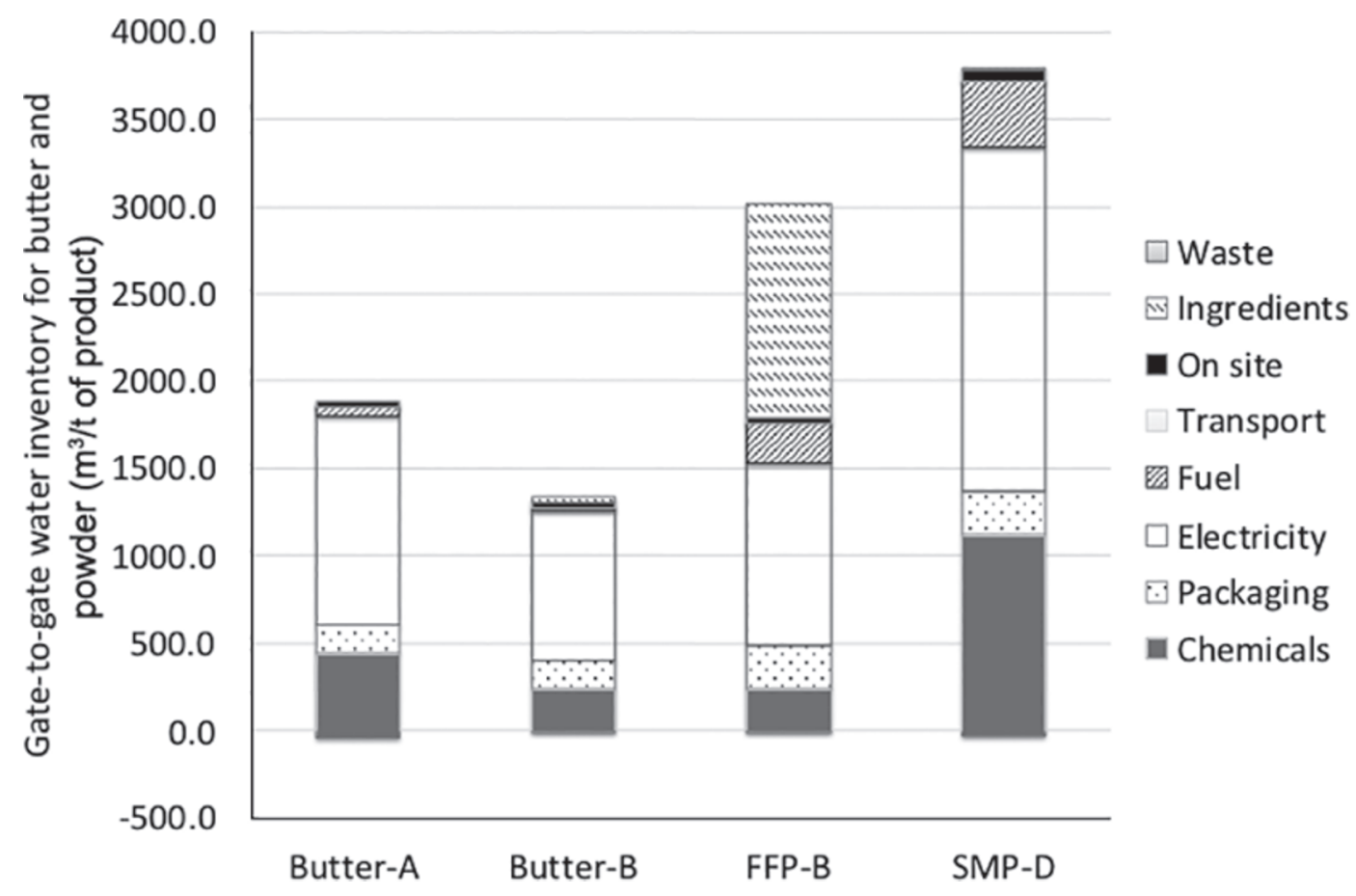

Figure 4. Gate-to-gate water inventory of butter and powder products from companies A, B, and D. FFP $=$ fat-filled powder, SMP $=$ skim milk powder.

\section{Comparison with Literature}

The volumetric water use in this study was generally comparable with reported values in the international literature. At the whole-site level, our results were consistent with the only other Irish study (Geraghty, 2011) and with international studies (Vourch et al., 2008; Boguniewicz-Zablocka et al., 2019; Mahatha et al., 2019). The reported separation and pasteurization water use was greater than that reported by Depping et al. (2017), but butter water use was at the lower end compared with Dvarioniene et al. (2012) and Ajiero and Campbell (2018). The evaporation and spray drying water use was comparable with Depping et al. (2017).

In terms of water-related environmental impacts, we found similar EP for butter as reported in the literature using the same impact method (Djekic et al., 2014). When switching to the ReCiPe Midpoint $(\mathrm{H})$ impact method (Goedkoop et al., 2009) used by Finnegan et al. (2017), the results were also comparable. Nilsson et al. (2010) did not provide a breakdown of contributions from the processing stage and therefore could not be compared. Mahatha et al. (2019) reported a significantly lower EP of butter using the aquatic eutrophication method in IMPACT 2002+ (Jolliet et al., 2003), but these results were difficult to interpret because the authors did not provide enough detail about water use breakdown or allocation to butter products.

\section{Opportunities for Water Efficiency Improvement at the Site Level}

Total water use varied among the 4 companies, which reflected differences in site-specific infrastructure as well as operational efficiency. For example, evaporator 1 at company $\mathrm{B}$ used twice as much water as evaporator 2 at company B. This was because evaporator 1 was built and installed in the 1970s and had far less contact surface than the newer evaporator 2. Product mix also affected water use. Based on milk processed, company D used the most water and generated the greatest amount of effluent (Table 1). Based on fresh water supplied, company B generated the most effluent and company $\mathrm{C}$ the least. Company B treated a significant amount of cow water in WWTP, whereas company $\mathrm{C}$ retained substantial amounts of the water from milk into cheese.

The one-way ANOVA indicated that electricity used for milk separation and pasteurization and utility significantly influenced monthly water use (Table 3 ). This reflected the seasonal production of these companies, where whole milk throughput during peak months (May and June) was 5 to 8 times that of the trough months (January). Electricity used for milk separation and pasteurization and utility were probably more sensitive to seasonal production than other factors, such as drying and wastewater treatment, and therefore were found to significantly affect monthly water use. 


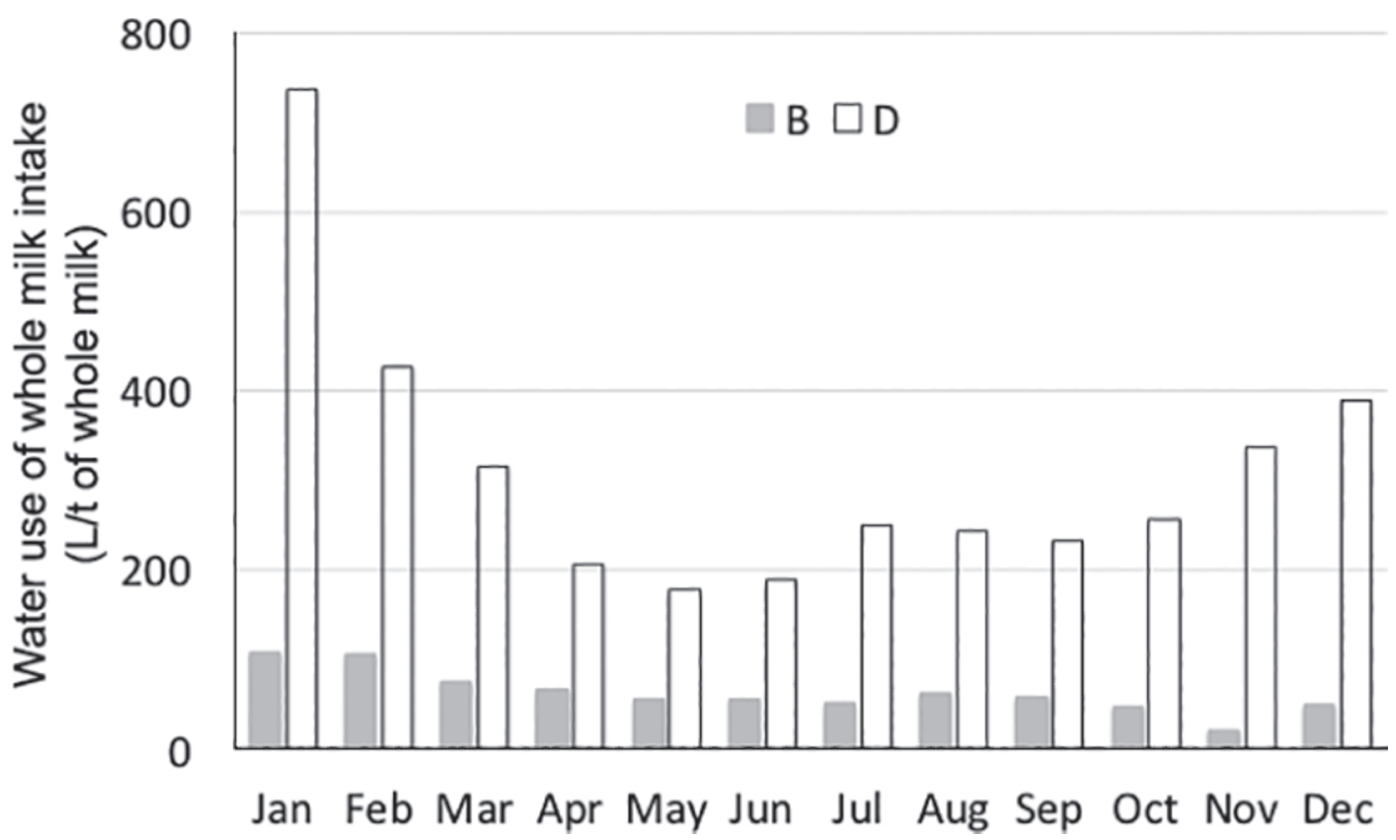

Figure 5. Water use of whole milk intake from companies B and D.

To improve water use efficiency throughout the whole site, a site-level optimization is needed to integrate processes in the water network (Buabeng-Baidoo et al., 2017) while considering the energy implications. Such an analysis was outside the scope of this study but hotspots (main contributors) were identified as a starting point.

Milk Intake. Water efficiency improvement can start at milk intake (delivery), where water is used for lorry wash (external) after every delivery and tanker wash every $24 \mathrm{~h}$ (internal). Condensate is sometimes used for lorry wash to reduce water use. Milk tanker

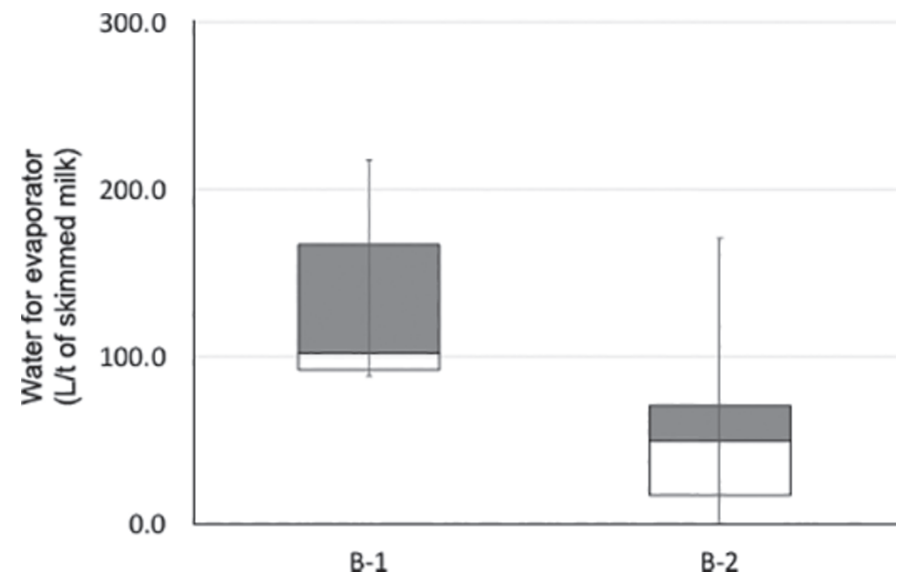

Figure 6. Water use for evaporation (evaporators 1 and 2) from company B. Boxes show the first and third quartile and median; whiskers show the maximum and minimum values of the distribution. wash involves (1) flushing with water to push milk residues to silos (this tends not be recorded); (2) detergent wash, and (3) final rinse with water. Only lorry tanker rinsing water was recorded for companies $\mathrm{B}$ and $\mathrm{D}$ because the detergent solution was recycled depending on conductivity. Company D used a significantly greater amount of water $(260.6 \mathrm{~L} / \mathrm{t}$ of milk) for lorry tanker wash than company B $(60.8 \mathrm{~L} / \mathrm{t}$ of milk). Leakage in company D's milk intake area was unlikely the reason because this difference was consistent throughout the year. Operator behavior might explain the large differences observed but this requires further investigation.

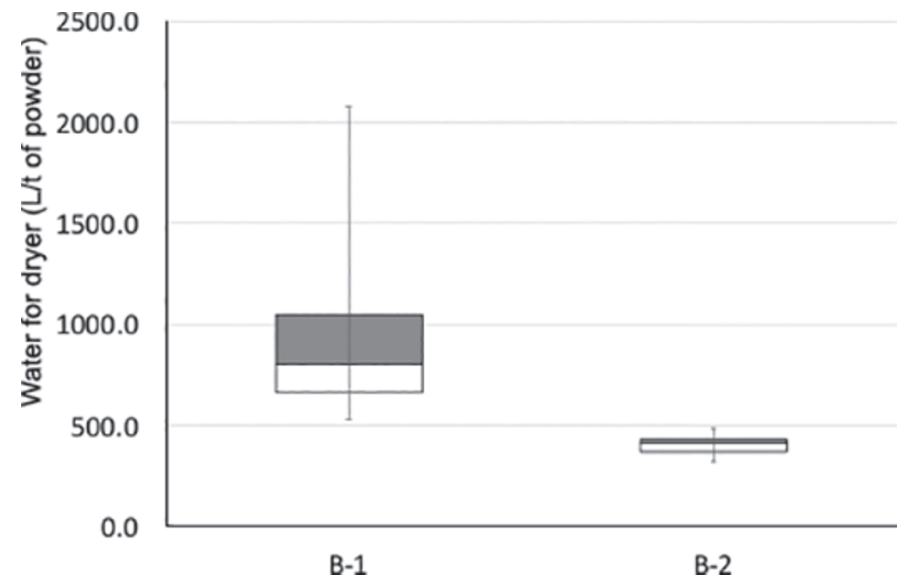

Figure 7. Water use for drying (dryers 1 and 2) from company B. Boxes show the first and third quartile and median; whiskers show the maximum and minimum values of the distribution. 
Table 3. Results of one-way ANOVA

\begin{tabular}{ll}
\hline Process $^{1}$ & \multicolumn{1}{c}{$P$-value } \\
\hline Milk.sep & $1.69 \mathrm{E} 05^{* * *}$ \\
Butter & 0.4037 \\
SMP.evap.dry & 0.6955 \\
Utility & $9.46 \mathrm{E} 07^{* * *}$ \\
WWTP & 0.5962 \\
Steam.gen & $0.0135^{*}$ \\
Prod.milk.DM & $0.0094^{* *}$ \\
COD.inflow & $0.0128^{*}$ \\
Milk.sep.percent & $0.0120^{*}$ \\
\hline
\end{tabular}

${ }^{1}$ Milk.sep $=$ separation and pasteurization electricity for whole milk $(\mathrm{kWh} / \mathrm{t}$ of milk); Butter $=$ butter plant electricity $(\mathrm{kWh} / \mathrm{t}$ of butter $)$; SMP.evap.dry $=$ skim milk powder $(\mathrm{SMP})$ evaporation and drying electricity $(\mathrm{kWh} / \mathrm{t}$ of SMP); Utility = utility electricity (boiler house and combined heat and power, refrigeration, compressed air, $\mathrm{kWh} / \mathrm{t}$ of milk); WWTP = electricity used by wastewater treatment plant $\left(\mathrm{kWh} / \mathrm{m}^{3}\right.$ of effluent $)$; Steam.gen = steam generated, $\mathrm{kg}$ of steam $/ \mathrm{t}$ of total milk processed; Prod. milk. DM = ratio of total product DM to milk solids (\%); COD.inflow = chemical oxygen demand (COD) of WWTP inflow ( $\mathrm{mg}$ of $\left.\mathrm{O}_{2} / \mathrm{L}\right)$; and Milk.sep.percent = monthly milk separation against annual total (\%).

*** $P<0.001,{ }^{* *} P<0.01,{ }^{*} P<0.1$.

Water use efficiency was found to be poor during January and December (Figure 5). Considering that WWTP capacity was underutilized during these months, this may not be a significant issue for the processor. Nevertheless, it remains an opportunity for improvement because the overall contribution of milk intake water use was important (7 and $13 \%$ to companies B and D respectively).

Fixing Leaks. Leakages occur in pipes, jacketed vessels, and heat exchangers. For example, refrigeration make-up water due to leaks from the refrigeration system ranged from 2.4 to $6.1 \%$ of fresh water supplied for companies A, B, and D (Figure 2). This potential area of improvement could be addressed with little effort and substantial benefit.

\section{Reducing WWTP Inflows}

The WWTP inflow consists of both condensate (23 to $41 \%$ ) and effluent from individual plants (59 to $77 \%$ ). To ensure inflow is kept within the capacity of the WWTP, Irish processors need to (1) reduce water intensity of CIP; (2) recover CIP solutions; (3) reduce the amount of condensate sent to WWTP; or (4) a combination of all of these (Figure 2).

Taking a dryer as an example, to achieve (1), the options include (a) running the dryer for longer to reduce the frequency of CIP; or (b) optimizing dryer operation so that less water is needed for each CIP. In terms of (a), this is constrained by the milk supply to the processor as well as the equipment size. In terms of (b), one company confirmed that all CIP was done manually and this was dependent on operator experience.
The water records of dryers indicated that for similar CIP routines that took the same length of time, daily CIP water use could vary by a factor 3 . This suggested a significant improvement opportunity in closing the gap among operators.

To achieve (2), membrane technology is required to recover CIP detergent. This would also help reduce the chemicals used for CIP. The processors only recycle CIP solutions used for lorry tankers, silos, and feeding lines to silos, whereas CIP solutions for separation, pasteurization, butter plant, evaporators, and dryers are discarded after a single use. This is partly due to a lack of on-site CIP recovery facilities. Research has shown that membranes can effectively recover common CIP chemicals such as caustic soda and nitric acid (Suárez et al., 2012) and the payback period can be as low as 1.8 yr (Fernández et al., 2010). This is a significant opportunity for Irish processors in the future.

To achieve (3), a significant opportunity lies in the reuse of cow water as process water. Vourch et al. (2008) found that 20 to $48 \%$ of water used by 11 French dairy processors was from cow water. In the current study, not all cow water was measured, and therefore the contribution was unknown. Using condensate has been found to lower water use in some Irish dairy processors (Green Business, 2016). Pioneering dairy plants in New Zealand have demonstrated that water demand can be completely satisfied by condensate (https://www .gea.com/en/technology-talks/zero-water.jsp). For the studied companies, boiler feed water was mostly made of cow water and this was reflected by the small amount of fresh water used for boiler feed (Figure 2). However, considering that the top-up amount of a running boiler is dependent on its blowdown rate, which is reasonably small, most of the cow water is used elsewhere; for example, in heat exchangers and CIP solutions. Filtration of cow water with membranes is required before reuse and cost needs to be considered. Regulations on using potable water by the food industry remain a barrier for water recycling but this is being changed in some sectors, including the dairy industry (FDA, 2015). It is likely that more guidelines will be provided in the future regarding water recover and reuse in the dairy industry.

\section{Water Efficiency Opportunities at the Supply-Chain Level}

Despite significant concern of processors, on-site water use was only a small contributor to gate-to-gate water use and this was consistent for both butter and powder products. For example, electricity generation required 26 to 38 times more water than on-site water use (per functional unit). This was mainly because of 
the water used as cooling water make-up, boiler makeup, and for emission control. Chemicals (e.g., sodium hydroxide) and packaging (e.g., cardboard boxes and paper bags) were also important contributors. In the case of FFP-B, however, the additional ingredient (vegetable oil) was the predominant contributor, and this was mainly because of the water requirement during the vegetable oil refining stage and irrigation during agricultural production. This highlighted the significant opportunities outside of the processing site over which the industry could exert some influence.

\section{EP of Products}

For EP, on-site emissions from WWTP were dominant or comparable to off-site contributors such as transportation, energy, and chemicals. The main emission from transportation was nitrogen dioxide from fuel combustion, and the main emission from electricity and chemicals was phosphate from disposal of spoils from coal mining. On-site emissions from WWTP were particularly important for company A, where treated effluent contained significantly greater amounts of total $\mathrm{N}$ and $\mathrm{NH}_{3}-\mathrm{N}$ than other companies (Table 1), which in turn led to significantly greater EP of butter-A and SMP-A. In fact, company A exceeded its license limit for $\mathrm{NH}_{3}-\mathrm{N}$ in 2015. This is crucial to processors, because future industry expansion will put more pressure on the capacity of WWTP.

\section{CONCLUSIONS}

A detailed analysis of water use efficiency across 4 Irish dairy processors identified the major contributors on site and along the gate-to-gate supply chain in terms of both volumetric water use and environmental impacts and benchmarked water use at the process level. Comprehensive metering is urgently needed to improving water use efficiency in light of ongoing expansion of dairy processing in Ireland. Significant opportunities exist to optimize operator behavior, cow water reuse, and off-site transportation, energy, and chemicals. The findings of this study represent a first attempt to define water efficiency opportunities at the site level and along the supply chain. Processors need to be aware of off-site contributors that significantly affect both the volumetric water use and the environmental impacts.

\section{ACKNOWLEDGMENTS}

This work was supported by the Irish State through funding from the Dairy Processing Technology Centre research programme funded by Enterprise Ireland (grant number TC/2014/0016). We acknowledge the collaboration of anonymous companies. We also acknowledge support from Alan Ryan, Greg Lohan, and Elaine O'Connor (University of Limerick, Ireland).

\section{REFERENCES}

Ajiero, I., and D. Campbell. 2018. Benchmarking water use in the UK food and drink sector: Case study of three water-intensive dairy products. Water Conserv. Sci. Eng. 3:1-17.

Bai, X., X. Ren, N. Z. Khanna, N. Zhou, and M. Hu. 2018. Comprehensive water footprint assessment of the dairy industry chain based on ISO 14046: A case study in China. Resour. Conserv. Recycling 132:369-375. https://doi.org/10.1016/j.resconrec.2017 .07 .021 .

Boguniewicz-Zablocka, J., I. Klosok-bazan, and V. Naddeo. 2019. Water quality and resource management in the dairy industry. Environ. Sci. Pollut. Res. Int. 26:1208-1216. https://doi.org/10.1007/ s11356-017-0608-8.

Bord Bia. 2017. Export Performance \& Prospects 2017-2018. Accessed May 30, 2018. https://www.bordbia.ie/industry/ manufacturers/insight/publications/MarketReviews/Documents/ ExportPerformanceProspects2017-2018.pdf.

Buabeng-Baidoo, E., N. Mafukidze, J. Pal, S. Tiwari, B. Srinivasan, T. Majozi, and R. Srinivasan. 2017. Study of water reuse opportunities in a large-scale milk processing plant through process integration. Chem. Eng. Res. Des. 121:81-91. https://doi.org/10.1016/j .cherd.2017.02.031.

Chambers, J. M., A. Freeny, and R. M. Heiberger. 1992. Analysis of variance; designed experiments. Chapter 5 of Statistical Models in Simulation. J. M. Chambers and T. J. Hastie, ed. Wadsworth \& Brooks/Cole. Springer, Berlin, Germany.

Ciroth, A., S. Muller, B. Weidema, and P. Lesage. 2016. Empirically based uncertainty factors for the pedigree matrix in ecoinvent. Int. J. Life Cycle Assess. 21:1338-1348.

CSO. 2017. Intake of Cows Milk by Creameries and Pasteurisers by Domestic source. Central Statistics Office, Cork, Ireland. Accessed Jan. 14, 2019. https://cso.ie/px/pxeirestat/Database/eirestat/ Milk\%20Production/Milk\%20Production_statbank.asp?SP=Milk $\% 20$ Production\&Planguage $=0$.

DAFM. 2010. Food Harvest 2020-A vision for Irish agri-food and fisheries. Department of Agriculture, Food and the Marine, Dublin, Ireland. Accessed Jun. 28, 2019. https://www.agriculture gov.ie/media/migration/foodindustrydevelopmenttrademarkets/ a gri - foodandtheeconomy/foodharvest 2020 / 2020FoodHarvestEng240810.pdf.

Daufin, G., J.-P. Escudier, H. Carrère, S. Bérot, L. Fillaudeau, and M. Decloux. 2001. Recent and emerging applications of membrane processes in the food and dairy industry. Food Bioprod. Process. 79:89-102. https://doi.org/10.1205/096030801750286131.

Depping, V., M. Grunow, C. van Middelaar, and J. Dumpler. 2017. Integrating environmental impact assessment into new product development and processing-technology selection: Milk concentrates as substitutes for milk powders. J. Clean. Prod. 149:1-10. https:// doi.org/10.1016/j.jclepro.2017.02.070.

Djekic, I., J. Miocinovic, I. Tomasevic, N. Smigic, and N. Tomic. 2014. Environmental life-cycle assessment of various dairy products. J. Clean. Prod. 68:64-72.

Dvarioniene, J., J. Kruopiene, and J. Stankevičiene. 2012. Application of cleaner technologies in milk processing industry to improve the environmental efficiency. Clean Technol. Environ. Policy 14:10371045. https://doi.org/10.1007/s10098-012-0518-x.

FDA. 2015. Grade "A" Pasteurized Milk Ordinance. Accessed July 18, 2018. https://www.fda.gov/downloads/food/guidanceregulation/ guidancedocumentsregulatoryinformation/milk/ucm513508.pdf.

Fernández, P., F. A. Riera, R. Álvarez, and S. Álvarez. 2010. Nanofiltration regeneration of contaminated single-phase detergents used in the dairy industry. J. Food Eng. 97:319-328. https://doi.org/10 .1016/j.jfoodeng.2009.10.023.

Finnegan, W., J. Goggins, E. Clifford, and X. Zhan. 2017. Environmental impacts of milk powder and butter manufactured in the 
Republic of Ireland. Sci. Total Environ. 579:159-168. https://doi .org/10.1016/j.scitotenv.2016.10.237.

Geraghty, R. 2011. Resource Efficiency in Ireland's Dairy Processing Sector. Enterprise Ireland, Dublin, Ireland.

Gerbens-Leenes, P. W., A. Y. Hoekstra, and T. van der Meer. 2009. The water footprint of energy from biomass: A quantitative assessment and consequences of an increasing share of bio-energy in energy supply. Ecol. Econ. 68:1052-1060. https://doi.org/10.1016/ j.ecolecon.2008.07.013.

Goedkoop, M., R. Heijungs, M. Huijbregts, A. De Schryver, J. Struijs, and R. Van Zelm. 2009. ReCiPe 2008. A life cycle impact assessment method which comprises harmonised category indicators at the midpoint and the endpoint level. First ed. Report I: Characterisation. Ministry of Infrastructure and the Environment, the Hague, the Netherlands.

Green Business. 2016. Comparing Best Practices in the Dairy Industry for CIP of Milk Evaporators to Identify Savings. Accessed Nov. 5, 2018. https://greenbusiness.ie/wp-content/uploads/2016/11/ Irelands-Dairy-Industry.pdf.

ISO. 2006. ISO 14040: Environmental management—Life cycle assessment: Principles and framework. International Organization for Standardization, Geneva, Switzerland.

ISO. 2014. ISO 14046 Environmental management-Water footprint: Principles, requirements and guidelines. International Organization for Standardization, Geneva, Switzerland.

Jolliet, O., M. Margni, R. Charles, S. Humbert, J. Payet, G. Rebitzer, and R. Rosenbaum. 2003. IMPACT 2002+: A new life cycle impact assessment methodology. Int. J. LCA 8:324-330.

Lovarelli, D., J. Bacenetti, and M. Fiala. 2016. Water Footprint of crop productions: A review. Sci. Total Environ. 548-549:236-251. https://doi.org/10.1016/j.scitotenv.2016.01.022.

Mahatha, C. S., K. M. Kani, and B. Dubey. 2019. Gate-to-gate environmental impacts of dairy processing products in Thiruvananthapuram, India. Resour. Conserv. Recycling 141:40-53. https://doi .org/10.1016/j.resconrec.2018.09.023.

Nilsson, K., A. Flysjö, J. Davis, S. Sim, N. Unger, and S. Bell. 2010. Comparative life cycle assessment of margarine and butter con- sumed in the UK, Germany and France. Int. J. Life Cycle Assess. 15:916-926. https://doi.org/10.1007/s11367-010-0220-3.

Nutter, D. W., D. S. Kim, R. Ulrich, and G. Thoma. 2013. Greenhouse gas emission analysis for USA fluid milk processing plants: Processing, packaging, and distribution. Int. Dairy J. 31:S57-S64. https://doi.org/10.1016/j.idairyj.2012.09.011.

Prasad, P., R. Pagan, M. Kauter, and N. Price. 2005. Eco-efficiency for the dairy processing industry. The UNEP Working Group for Environmental Management Centre. University of Queensland, St. Lucia, Australia.

PRé Consultants. 2019. SimaPro 8.2 LCA software. PRé Consultants, Amersfoort, the Netherlands.

R Core Team. 2018. R: A language and environment for statistical computing. R Core Team, Vienna, Austria.

Suárez, L., M. A. Díez, R. García, and F. A. Riera. 2012. Membrane technology for the recovery of detergent compounds: A review. J. Ind. Eng. Chem. 18:1859-1873. https://doi.org/10.1016/j.jiec 2012.05 .015$.

van Oers, L. 2015. CML-IA database, characterisation and normalisation factors for midpoint impact category indicators, version 4.5 . Leiden University, the Netherlands. Accessed Jun. 28, 2019. https: //www.universiteitleiden.nl/en/research/research-output/science/ cml-ia-characterisation-factors.

Vourch, M., B. Balannec, B. Chaufer, and G. Dorange. 2008. Treatment of dairy industry wastewater by reverse osmosis for water reuse. Desalination 219:190-202. https://doi.org/10.1016/j.desal .2007.05.013.

Wojdalski, J., B. Drózdz, J. Piechocki, M. Gaworski, Z. Zander, and J. Marjanowski. 2013. Determinants of water consumption in the dairy industry. Pol. J. Chem. Technol. 15:61-72. https://doi.org/ 10.2478/pjct-2013-0025.

Yan, M., and N. M. Holden. 2018. Life cycle assessment of multiproduct dairy processing using Irish butter and milk powders as an example. J. Clean. Prod. 198:215-230. https://doi.org/10.1016/j .jclepro.2018.07.006. 